\title{
O QUE A ANTROPOLOGIA TEM A VER COM A NECROPOLÍTICA?
}

RESENHA DE: MBEMBE, ACHILLE. NECROPOLÍTICA: BIOPODER, ESTADO DE EXCEÇÃO, POLÍTICA DA MORTE. TRADUZIDO POR RENATA SANTINI. SÃO PAULO: N-1 EDIÇÕES, 2018.

Cleiton de Jesus Rocha ${ }^{1}$

http://lattes.cnpq.br/0813123511131004

https://orcid.org/0000-0001-6723-2453

\section{Arielson Teixeira do Carmo² \\ http://lattes.cnpq.br/8771087410813687 https://orcid.org/0000-0003-1149-7668}

Recebido em: 13 de setembro de 2019.

Aprovado em: 25 de novembro de 2019.

\section{Achille Mbembe}

\section{NECROPOLÍTICA}

$n-1$
As ciências sociais na América Latina necessitam passar por um processo de descolonização de, no mínimo, duas dimensões: a primeira é política; a segunda, ética. Partindo desse ponto, Achille Mbembe, no livro intitulado Necropolítica, trata de uma questão fundamental: o modo como o poder estatal pode produzir, gerenciar e tornar aceitável a produção de corpos matáveis - ou, nos termos de Mbembe (2018), "mortosvivos".

O foco de análise do seu livro está diretamente relacionado aos subalternos, cujas formas e corpos precisam ser explicitados e especificados. A necropolítica nas periferias das grandes metrópoles brasileiras se expressa, por exemplo, no fato de que jovens negros (pretos e pardos) e policiais negros são os que mais morrem numa política de segurança pública fracassada. Além disso, o índice de assassinatos e violência contra a população LGBTQIA+ e as mulheres ${ }^{3}$ no Brasil é um dos

\footnotetext{
${ }^{1}$ Mestrando pelo Programa de Pós-Graduação em Antropologia Social da Universidade Federal do Rio Grande do Sul PPGAS - UFRGS Graduado em licenciatura sociologia pela Universidade Federal do Amapá - UNIFAP. Membro do núcleo de estudos da religião - NER/UFRGS. Membro do Centro de Estudos Políticos, Religião e Sociedade - CEPRES/UNIFAP. Vinculado ao Laboratório de Estudos Etnográficos - LAET/UNIFAP. E-mail: clei2014cs@hotmail. $\underline{\mathrm{com}}$

2 Doutorando em Sociologia pela Universidade Federal de Pelotas. Mestre em Sociologia pela Universidade Federal de Pelotas - UFPel . Graduado no Curso de Licenciatura e Bacharelado em Ciências Sociais pela Universidade Federal do Amapá - UNIFAP. Foi Bolsista voluntário Grupo PET - Programa de Educação Tutorial; Bolsista de Iniciação Cientifica - PROBIC - UNIFAP. Membro do Centro de Estudos Políticos Religião e Sociedade - CEPRES. E-mail: arielsondocarmo@gmail.com

${ }^{3}$ Mbembe (2018, p. 40) afirma que "opressão e pobreza severas foram experimentadas com base na raça e classe social" e que "Tais obrigações foram cruciais para determinar o valor das pessoas e utilidade." (MBEMBE, 2018, p.56).
} 
mais altos do mundo. Os indígenas também são um alvo notório de gerenciamento da máquina de morte que é o Estado brasileiro. Nesse contexto, a necropolítica de Mbembe (2018) direciona nosso olhar para um movimento político que atinge corpos subalternizados.

Achille Mbembe é um filosofo africano nascido em Camarões, e atualmente é professorinvestigador de História e Política no Instituto de Pesquisa W. E. B. Dubois da Universidade Harvard. O livro Necropolítica é um ensaio que tem como temática os conceitos de biopoder, soberania, estado de exceção e política da morte. Podemos entrever, assim, as influências de autores como Michel Foucault (na ideia de biopoder) e de Hannah Arendt (nas categorias de política e soberania).

Mbembe define soberania como um pressuposto de ditar quem pode viver ou morrer, ou seja, "ser soberano é exercer controle sobre a mortalidade e definir a vida como a implementação e manifestação do poder” (MBEMBE, 2018, p.5). Nesse contexto, o filósofo destoa da visão clássica de soberania de um Estado, restrita à ideia de legitimidade para convocar uma guerra e definir suas políticas internas. Até então, morrer através da guerra não era percebido como uma política de gerenciamento de corpos marcados para morrer. Na perspectiva weberiana, o Estado moderno tem como principal característica reivindicar para si a prática repressiva, ou seja, o monopólio legítimo da violência ${ }^{4}$. Entretanto, Weber não previu que, no decorrer dos séculos XX e XXI, outros grupos, instituições ou mesmo pessoas acabariam acionando a violência como uma tecnologia de manutenção de seus poderes, inclusive confrontando o Estado moderno no exercício desse poder e sem ter sua legitimidade de sua violência questionada.

Mbembe chama atenção para as formas como o Estado lida com essa problemática através da política, definida duplamente como "um projeto de autonomia e a realização de um acordo em coletividade mediante comunicação e reconhecimento” (MBEMBE, 2018, p. 9). O autor também enfatiza que é tal acordo que "a diferencia da guerra". Dessa forma, a política agiria como ordenadora e gerenciadora da morte, ao mesmo tempo em que, na esfera pública, buscaria tornar justificável sua própria ação ${ }^{5}$. Logo, a soberania seria explicitamente ordenada pelo direito de liquidar as pessoas subalternizadas.

Dentro dessa configuração, o que marcaria ou estruturaria a necropolítica seria sua associação com a colonialidade, e a raça seria usada como uma tecnologia de enquadramento e subjugação dos povos, uma marca da colonização, adotada pelos Estados-nação:

A raça foi a sombra sempre presente no pensamento e na prática das políticas do Ocidente, especificamente quando se trata de imaginar a desumanização de povos estrangeiros - ou a dominação a ser exercida sobre eles [...] O racismo é acima de tudo uma tecnologia destinada a permitir o exercício do biopoder - "este velho direito soberano de matar" (MBEMBE, 2018, p.18).

E nessa perspectiva, Mbembe vai ao encontro do que afirma Quijano (2005, p.138):

\footnotetext{
4 "Uma empresa com caráter de instituição política denominamos Estado [...] na medida em que seu quadro administrativo reivindica com êxito o monopólio legítimo da coação física para realizar as ordens vigentes” (WEBER, 1999, p. 34).

5 Penso contemporaneamente na América Latina e, especificamente, na Colômbia e Brasil, países em que a morte de lideranças ambientais, indígenas e de movimentos sociais parte propriamente das consequências oriundas da necropolítica incorporada pelos Estados nacionais. "Os danos persistentes à vida civil são particularmente eloquentes (acentuados)." (MBEMBE, 2018, p.50, grifos nossos).
} 
A dominação é o requisito da exploração, e a raça é o mais eficaz instrumento de dominação que, associado à exploração, serve como o classificador universal no atual padrão mundial de poder capitalista.

Aqui, podemos perceber que há um processo de articulação entre o próprio exercício de poder dos Estados nacionais com uma lógica econômica capitalista, englobando, também, a raça. Nesse sentido, no Brasil contemporâneo a lógica de mercado trabalha para justificar as práticas necropolíticas da classe racialmente dominante, tornando os corpos subalternizados descartáveis, numa perspectiva de raça e classe. Junto a esse processo, a ocupação de espaços subalternizados funciona dentro da divisão racial do trabalho e das fronteiras interétnicas. O sistema simbólico dominante naturaliza a circulação dos corpos subalternizados em determinados espaços, de modo a rotulá-los como exploráveis, matáveis e subjugáveis.

O Estado é uma instituição com tecnologias de gerenciamento desse modelo de poder, ordenando e legitimando a operacionalidade do necropoder. Mbembe vê o Estado ${ }^{6}$ como aquele que tem a função de "civilizar" esse modus operandi de matar. Em síntese, o necropoder se apresenta como uma forma sutil de destruição de uma dada cultura. A soberania se relaciona com a capacidade de administrar o poder de ditar quem deve viver ou morrer. Dentre os vários exemplos desse modus operandi, o autor menciona o caso da Palestina, na qual os elementos produtores dessa lógica de gerenciamento da morte culminam na ocupação colonial.

Considerando esse fator, algo que queremos problematizar no fazer antropológico é que os sujeitos que embasam a produção do conhecimento antropológico são especificamente corpos subalternizados, e esses corpos sofrem com uma política que marca seus corpos para morrer. Assim, a nós, antropólogas e antropólogos, nos é demandado considerar que o saber produzido quando estabelecemos uma relação dialógica com os nossos interlocutores é engendrado e perpassado por políticas coloniais.

Desse modo, perguntar "o que a antropologia tem a ver com a necropolítica?" é chamar a atenção para o processo de construção do conhecimento atrelado à atuação dos Estados colonialistas dos séculos XIX e XX. Analogamente, essa marca acabou por definir o "objeto" da antropologia, como podemos perceber nas escolhas dos temas de pesquisa geralmente direcionados aos diversos grupos subalternizados contemporaneamente. É importante ressaltar que não estamos aqui fazendo um "denuncismo" superficial da antropologia - e, portanto, condenando a ciência antropológica em si -, mas sim enfatizando que a produção de conhecimento antropológico se deu numa situação colonial7.

Em convergência com Mbembe (2018), Edgardo Lander (2005) elabora uma genealogia das estruturas de saber e poder nas ciências sociais, acompanhando desde sua concepção pelo centro, ou sistema-mundo, até a chegada aos países "periféricos” (os subalternos), que se entrelaçam a essa lógica, como reprodutores, ou meros coadjuvantes no que diz respeito à produção das epistemologias. Nesse ínterim, e falando de forma kafkiana, estamos imersos nas

\footnotetext{
${ }^{6}$ O "Estado se comprometeria a "civilizar" os modos de matar e atribuir objetivos racionais ao próprio ato de matar." (MBEMBE, 2018, p.33); “O estado pode, por si mesmo, se transformar em uma máquina de guerra.” (MBEMBE, 2018, p.54) e "A centralidade do Estado no cálculo da guerra deriva do fato de que o Estado é o modelo de unidade política, um princípio de organização racional, a personificação da ideia universal e um símbolo de moralidade.” (MBEMBE, 2018, p.34)

7 Pensar o processo de descolonização é necessário à antropologia, principalmente devido ao modo como o saber antropológico foi engendrado e reproduz, até hoje, uma lógica de colonialidade - podemos dizer que as práxis antropológicas e a práxis da colonialidade estão politicamente imbricadas.
} 
estruturas de poder e nos deparamos com inúmeros labirintos, mas - diferente de Josef $\mathrm{K}$, que morre sem saber o motivo do seu processo - os subalternos têm clareza sobre o ponto de partida do seu "processo" e podem, assim, elaborar uma contranarrativa.

Edgardo Lander (2005) aborda uma dimensão ontológica, epistemológica e política. A primeira diz respeito ao modo como os indivíduos e os sujeitos subalternos têm suas perspectivas passadas pelo prisma dos poderes imperiais, e se veem na lógica do polo dominante. A segunda se refere ao fato de que o conhecimento ocidental parte, igualmente, do centro, e reverbera em outras regiões de produção do saber. E o poder, por sua vez, tem como substrato tecer e rebocar as demais estruturas. Como se ele fosse "por si mesmo", o universal, o ponto zero, que dispensa explicações.

Podemos considerar que essa crítica às ciências sociais pode suscitar um giro decolonial ${ }^{8}$, acerca de como antropólogas e antropólogos têm tratado sua construção epistemológica, e como a antropologia se introduz nesse contexto político de relações de poder. Muitas vezes, mesmo tendo-se consciência dessa dinâmica, a crítica pós-colonial, não é verdadeiramente incorporada dentro da epistemologia do fazer antropológico?.

Retomando o livro de Mbembe (2018), queremos agora sublinhar a preocupação do autor sobre a questão da liberdade:

Se observarmos a partir da perspectiva da escravidão ou da ocupação colonial, morte e liberdade estão irrevogavelmente entrelaçadas. Como já vimos, o terror é uma característica que define tanto os Estados escravistas quanto os regimes coloniais contemporâneos. Ambos os regimes são também instâncias e experiências específicas de ausência de liberdade. (MBEMBE, 2018, p. 68).

Na situação colonial, a ausência de liberdade é algo presente justamente por que as pessoas estão sujeitas à ação da necropolítica. E isso é tão gritante que o próprio ato de morrer dentro desses regimes seria percebido como ato de liberdade. Aqui, quase nos aproximamos do mito de sísifo diante de sua tragédia de empurrar uma pedra até o topo de uma montanha e vê-la deslizar novamente ladeira abaixo. Subir ao topo da montanha seria buscar um sopro para respirar, um pequeno instante de liberdade - leia-se vida -, mas não somos Sísifo.

Por fim, recomendamos o livro para estudantes de ciências sociais e humanidades, interessados no fenômeno do poder estatal e em conceitos como colonialidade, pós-colonialidade e decolonialidade. Afinal, a obra resenhada possibilita um amplo debate sobre assuntos pertinentes às relações de poder na modernidade. Ao mesmo tempo, o livro de Mbembe (2018) nos leva a refletir sobre a agência do poder da necropolítica e o modo pelo qual ela acaba influenciando a vida das pessoas que foram relegadas à subalternidade.

\section{REFERÊNCIAS}

BALLESTRÍN, Luciana. Para transcender a colonialidade. [Entrevista concedida a Luciano

\footnotetext{
8 "O giro decolonial procura responder às lógicas da colonialidade do poder, ser e saber, apostando em outras experiências políticas, vivências culturais, alternativas econômicas e produção do conhecimento obscurecidas, destruídas ou bloqueadas pelo ocidentalismo, eurocentrismo e liberalismo dominantes. Concebe a importância da interação entre teoria e prática, buscando dialogar com a gramática das lutas sociais, populares e subalternizadas dos povos que compuseram e compõem a invenção da ideia de América Latina.” (BALLESTRÍN, 2013).

${ }_{9}^{9}$ Sobre esse ponto em especial, conferir Carvalho (2001).
} 
Gallas e Ricardo Machado]. Revista do Instituto Humanitas Unisino, São Leopoldo, n. 431, nov. 2013.

CARVALHO, José Jorge de. O olhar etnográfico e a voz subalterna. Horizontes Antropológicos, Porto Alegre, ano 7, n. 15, p. 107-147, jul. 2001.

LANDER, Edgardo. Ciências sociais: saberes coloniais e eurocêntricos. In: LANDER, Edgardo (org). A colonialidade do saber: eurocentrismo e ciências sociais. Perspectivas latinoamericanas. Buenos Aires: Colección Sur Sur; CLACSO, 2005.

MBEMBE, Achille. Necropolítica: biopoder, estado de exceção, política da morte. Traduzido por Renata Santini. São Paulo: n-1 edições, 2018.

QUIJANO, Anibal. Colonialidade do poder, Eurocentrismo e América Latina. In: A colonialidade do saber: eurocentrismo e ciências sociais. Perspectivas latino-americanas. Buenos Aires: CLACSO, 2005.

WEBER, Max. Economia e sociedade: fundamentos da sociologia compreensiva. Brasília, DF: Ed. UnB: São Paulo: Imprensa Oficial do Estado de São Paulo, 1999. 2 v. 